\title{
Electricity Consumption and Economic Growth: Evidence from Poland
}

\author{
Rafał Kasperowicz \\ Poznań University of Economics \\ Poland \\ rafal.kasperowicz@ue.poznan.pl
}

\begin{abstract}
The paper investigates the relationship between electricity consumption and economic growth in Poland for the period 2000 to 2012. Understanding the behavior of electricity consumption in relation to the economy is very important for improve a stable economic growth and development. The obtained results indicate that there is the causal relationship between electricity consumption and economic growth in Poland and the relationship is bi-directional. We also discovered the bi-directional causality between capital and economic growth.

On the basis of the causality results we estimated a one-sector aggregate production function, where the electricity consumption was one of the input variables. The evaluated growth model showed that electricity consumption is a pro-growth variable, so the results indicate that economic growth of Poland is electricity-dependent. That's allows to state that electricity is a limiting factor to economic growth of Poland.
\end{abstract}

Keywords: Electricity consumption, Economic growth, Granger causality, Poland

JEL classification: L52, C53, P1

\section{INTRODUCTION}

The area of the relationship between electricity consumption and economic growth has been subject to active empirical research over the past two decades. Most studies conclude that there is a strong relationship between the two variables. Ferguson, Wilkinson and Hill (2000) found correlation between wealth creation and electricity use in 100 developing countries. The correlation was even stronger between wealth and electricity use then between total energy consumption and wealth. However, correlation is not the only measure of some dependences between variables. A very useful measure is causal relationship, and the causal relationship provides information on past electricity consumption movements improves forecasts of movements of economic growth.

There are many studies on the subject, and the studies differ from each other. First, a number of studies found bi-directional causality. Oh and Lee (2004) for Korea and Yoo (2005) also for Korea, Soytas and Sari (2003) for Argentina. Second come studies where unidirectional causality running from electricity consumption to GDP was founded. A strong evidence found Altinay and Karagol (2005) for Turkey, Lee and Chang (2005) for Taiwan, Soytas and Sari (2003) for Turkey, France, Germany and Japan. A third group are 
the studies that unidirectional causality running from economic growth to electricity consumption, these include the findings made by Fatai, Oxley, and Scrimgeour (2004) for New Zealand and Australia, Hatemi and Irandoust (2005) for Sweden. And finally the last group comprises studies that found no causal relationships between electricity consumption and economic growth, these are for example Wolde-Rufael (2006), Cheng (1995).

The aim of this paper is to empirically investigate the causal relationships between electricity consumption and economic growth in Poland over the sample period of 2000 to 2012. Understanding the behavior of electricity consumption in relation to the economy is very important for improve a stable economic growth and development, so the hypothesis of the study is that electricity is a limiting factor to economic growth of Poland. The causal relationships were obtained by the Granger-causality test. The causality results helped to develop the neo-classical one-sector aggregate production function using electricity consumption as one of the input variables. The analysis employed OLS model estimation except that the pre-selection of the model variables was determined by the results of the Granger-causality test.

The remainder of the paper is organized as follows. Section 2 describes the model and the econometric methodology used in the analysis. Section 3 reports the data employed in this study and the empirical results. Finally, conclusions are made in Section 4.

\section{THE METHOD AND THE MODEL}

For the investigation of the relationship between electricity consumption and output growth and for the estimation of the GDP equation, we propose a framework based on the conventional neo-classical onesector aggregate production function, where we treat Electricity Consumption (E), Capital (K) and Total Employment (L), as separate inputs. That is:

$$
G D P=f(K, L, E)
$$

The study of relationships between variables was conducted with the application of the econometric causality analysis developed by C. W. J. Granger (Granger 1969; Granger 1980).

Causal relationships are difficult to identify empirically. The contemporary concept of causality has three important features:

there is no instant causality as there is always some time between independent actions;

for the same reasons there is no mutual, simultaneous causal effect;

future values of variables cannot be the cause of the past.

The definition proposed by W. J. Granger refers only to stochastic variables and is based on the assumption that the future cannot determine the past. It is assumed that variable $x_{t}$ is the Granger-cause of variable $y_{t}$ only when the current values of $y$ may be described and forecast more accurately with the use of the past values of $x$ than without using them, given the unchanged set of information.

To put it simply, we may say that the Granger relevance test checks whether the regression model:

$$
y_{t}=\alpha_{0}+\alpha_{1} y_{t-1}+\ldots+\alpha_{k} y_{t-k}+\beta_{1} x_{t-1}+\ldots+\beta_{k} x_{t-k}+\varepsilon_{t}
$$

explains and predicts the response variable better than the following model:

$$
y_{t}=\alpha_{0}+\alpha_{1} y_{t-1}+\ldots+\alpha_{k} y_{t-k}+\varepsilon_{t} .
$$


The verification of causality in Granger's sense consists in the test of statistics $F$ for the null hypothesis in the following form $H_{0}: \beta 1=\ldots=\beta_{k}=0$, which means that $x$ is not cause $y$ in Granger's sense, with the rejection area for threshold likelihood $p=0.05$, or in the test $H_{0}$ with the use of Lagrange multiplier, the direct test statistics of which has the following form:

$$
L M F=\frac{T-h}{k} \cdot \frac{R_{0}^{2}}{1-R_{0}^{2}}
$$

where:

$T$ - sample size,

$h$ - number of variables in equation (2),

$k$ - number of variables in equation (3),

$R_{0}^{2}$ - determination coefficient for the estimated regression for the residuals of model (2) in relation to all variables from equation (2).

This statistics, with the assumption of the truthfulness of the null hypothesis, has distribution $F(k,(T-h))$. We should also adopt the level of relevance, which was $5 \%$ in the conducted analyses.

Thanks to the fact that we had conducted the relevance test in Granger's sense we were able to identify the maximum leads of explanatory variables considered to be the cause of the corresponding reference variable. The Granger test was carried out with the assumption of short-term relationships between variables, which meant the timespan of no more than one year. Therefore, the causality test in Granger's sense of the series of explanatory variables compared to the reference values was conducted for the leads of $1,2,3,4$ quarters.

Eventually, the Granger test indicates the maximum relevant leads of explanatory variables viewed as a cause. Hence, for example, the fact that we indicate the relevant lead of four periods suggests that we should include five series of the explanatory variable with the lead of $0,1,2,3,4$ periods in the regression equation of the response variable (Kasperowicz 2012; Kasperowicz 2013).

It is assumed that the analyzed time series consist of: random, seasonal, cyclical fluctuations and a longterm trend. Thus, at this stage of the research, the following GDP equation of multiple regression was designed:

$$
G D P_{t}=\beta_{0}+\sum_{i=0}^{n} \beta_{1 i} K_{t-i}+\sum_{i=0}^{n} \beta_{2 i} L_{t-i}+\sum_{i=0}^{n} \beta_{3 i} E_{t-i}+\sum_{i=1}^{4} \beta_{8 i} q_{i}+\beta_{9} T+\mu_{t}
$$

where:

E - Electricity Consumption,

$K \quad-$ Gross Fixed Capital,

$L \quad$ - Total Employment,

$n-$ maximum lag of the variable determined by the results of the Granger causality test,

$\sum_{i=1}^{4} \beta_{8 i} q_{i}-$ seasonal fluctuations,

$\mathrm{T}-$ trend (time),

$\mu_{t} \quad-$ error term. 
Thanks to the application of multiple regression with the procedure of stepwise regression we were able to reduce the set of explanatory variables leading by $n$-times to the most relevant leads of particular explanatory variables.

Stepwise regression is the most commonly used method of choosing explanatory variables. At each stage of the estimation of a model, the evaluation of each variable's relevance is revised. This procedure reduces the risk that the model will not include a relevant variable or that it will include an irrelevant one.

\section{EMPIRICAL RESULTS}

\section{Data and variables definitions}

The data for calculation was taken from OECD statistic databases. The financial data was adapted to reality with the use of price indicators. The research covers the period from the first quarter of 2000 to the fourth quarter of 2012. The variables' notations are as follows:

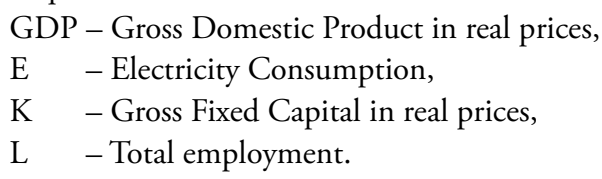

\section{Test results for unit roots and stationarity}

Before conducting any further analysis, the applied time series were examined by ADF (Augmented Dickey-Fuller) to find the existence of a unit root and by the KPSS test to test for stationarity. The tests are needed because the applied Granger causality test assumes the stationarity of the analyzed time series. The ADF null hypothesis tested is that the variable under investigation has a unit root against the alternative that it does not. The lag-length of the test is chosen using the Akaike Information Criteria after taking for first and higher order serial correlation in the residuals. KPSS tests are used for testing a null hypothesis that an observable time series is stationary (Kwiatkowski, Phillips, Schmidt, Shin, 1992). KPSS type tests are intended to complement unit root tests, such as the Dickey-Fuller tests.

Table 1

Test results for unit roots and stationarity

\begin{tabular}{lcccccccc}
\hline \multicolumn{1}{c}{ Variable } & $\mathrm{GDP}$ & $\mathrm{E}$ & $\mathrm{K}$ & $\mathrm{L}$ & $\Delta \mathrm{GDP}$ & $\Delta \mathrm{E}$ & $\Delta \mathrm{K}$ & $\Delta \mathrm{L}$ \\
\hline ADF & 1,87 & $-1,62$ & 0,70 & $-0,11$ & $\mathbf{- 7 , 3 9}$ & $\mathbf{- 2 , 8 0}$ & $\mathbf{- 7 , 4 9}$ & $-1,45$ \\
Asymptotic p-value & 0,99 & 0,47 & 0,99 & 0,94 & $2,74 \mathrm{e}-011$ & 0,05 & $1,416 \mathrm{e}-011$ & 0,55 \\
\hline KPSS & $\mathbf{1 , 4 1}$ & 0,73 & $\mathbf{1 , 3 2}$ & $\mathbf{1 , 0 6}$ & $\mathbf{0 , 2 7}$ & $\mathbf{0 , 2 5}$ & $\mathbf{0 , 2 6}$ & $\mathbf{0 , 2 2}$ \\
Critical value (5\%) & 0.47 & 0,47 & 0.47 & 0.47 & 0.47 & 0.47 & 0.47 & 0.47 \\
\hline
\end{tabular}

Source: own calculation.

Table 1 reports the results of testing for unit roots and stationarity in the level variables as well as in their first difference. In the first half of the table the null hypothesis that each variable has a unit root cannot be rejected (ADF). The KPSS null hypothesis that each variable http://en.wikipedia.org/wiki/Time_series is stationary cannot be rejected, either. However, after applying the first difference, three of the variables meet 
the requirements of the study. Only in the case of Total Employment $(\mathrm{L})$ is there no confidence about the stationarity (ADF statistic), which results in removing this variable from further research. In the case of the other time series, I can acknowledge their stationarity for the $95 \%$ confidence interval.

\section{Test results for Granger-causality}

In studying causality in Granger's sense, we assumed the existence of relevant relationships between the explanatory variables and the reference variable of up to 4-quarter lead, which is determined by the shortterm scope of research. The relevance level of 5\% - as in the case of the other tests - was assumed. The results of testing for the causality are reported in Table 2, which presents the significant causality for each pair of variables with the highest significant lag. The results were obtained using EViews software.

Pairwise Granger Causality Tests

\begin{tabular}{|c|c|c|c|}
\hline Null Hypothesis: & Lag & F-Statistic & Prob. \\
\hline$\Delta$ E does not Granger Cause $\Delta$ GDP & 3 & 3.11309 & 0.0365 \\
\hline$\Delta$ GDP does not Granger Cause $\Delta \mathrm{E}$ & 3 & 4.41270 & 0.0089 \\
\hline$\Delta$ K does not Granger Cause $\Delta$ GDP & 4 & 4.52273 & 0.0044 \\
\hline$\Delta$ GDP does not Granger Cause $\Delta \mathrm{K}$ & 2 & 25.5436 & 4. E- 08 \\
\hline
\end{tabular}

Source: own calculation.

The results of the Granger-causality tests indicate that Granger-causality is running in both directions between Electricity Consumption and Gross Domestic Product and in both directions between Gross Fixed Capital and Gross Domestic Product. The conclusions regarding Electricity Consumption of the Polish economy are contrary to the neo-classical argument that energy is neutral to output growth. The obtained results for Poland are consistent with the view that energy consumption does have a causal impact on economic growth. The findings are in line with the findings of Oh and Lee (2004), Yoo (2005), Soytas and Sari (2003), who obtained similar results on other countries.

\section{The estimation of the GDP model}

The Granger-causality tests of short-term relationships let us conclude that two of the examined independent variables turned out to be relevant. It means that they may be helpful in forecasting the reference variable. The obtained test results let us develop Equation (5) into the following form: 


$$
\Delta G D P_{t}=\beta_{0}+\sum_{i=0}^{4} \beta_{1 i} \Delta K_{t-i}+\sum_{i=0}^{3} \beta_{3 i} \Delta E_{t-i}+\sum_{i=1}^{4} \beta_{8 i} q_{i}+\beta_{9} T+\mu_{t}
$$

where:

$\triangle G D P$ - growth rates of Gross Domestic Product

$\triangle E \quad$ - growth rates of Electricity Consumption,

$\Delta K \quad$ - growth rates of Gross Fixed Capital.

In addition to being consistent with the Granger-causality results, the model in Equation (6) describes the type of interaction between GDP and input variables - whether it will be positive or negative, which is of great importance for the economic relevance of the model.

The results of the estimation of GDP equation are reported in Table 3.

Table 3

Model 1: OLS, using observations 2001:2-2012:4 Dependent variable: $\Delta$ GDP

\begin{tabular}{|c|c|c|c|c|}
\hline & Coefficient & Std. Error & t-ratio & p-value \\
\hline const & 0,0491603 & 0,039612 & 1,2410 & 0,22334 \\
\hline$\Delta \mathrm{E}$ & $-0,0238398$ & 0,0651683 & $-0,3658$ & 0,71683 \\
\hline$\Delta \mathrm{E} \_1$ & 0,0255294 & 0,0669958 & 0,3811 & 0,70560 \\
\hline$\Delta \mathrm{E} \_2$ & 0,11039 & 0,0676525 & 1,6317 & 0,11225 \\
\hline$\Delta \mathrm{E} \_3$ & 0,0479938 & 0,0646293 & 0,7426 & 0,46298 \\
\hline$\Delta \mathrm{K}$ & 0,0836261 & 0,0464786 & 1,7992 & 0,08113 \\
\hline$\Delta \mathrm{K} \_1$ & 0,0646213 & 0,037695 & 1,7143 & 0,09585 \\
\hline$\Delta \mathrm{K} \_2$ & 0,0399378 & 0,0385559 & 1,0358 & 0,30781 \\
\hline$\Delta \mathrm{K} \_3$ & $-0,0297077$ & 0,0377109 & $-0,7878$ & 0,43645 \\
\hline$\Delta \mathrm{K} \_4$ & 0,00869198 & 0,0522984 & 0,1662 & 0,86901 \\
\hline $\mathrm{dq} 1$ & $-0,123704$ & 0,0663953 & $-1,8631$ & 0,07136 \\
\hline $\mathrm{dq} 2$ & $-0,0177467$ & 0,0642894 & $-0,2760$ & 0,78424 \\
\hline dq3 & $-0,0134528$ & 0,063623 & $-0,2114$ & 0,83384 \\
\hline time & $-8,35934 \mathrm{e}-05$ & 0,000139618 & $-0,5987$ & 0,55344 \\
\hline Sum squared resid & & 0,004788 & sion & 0,012045 \\
\hline R-squared & \multicolumn{2}{|r|}{0,987361} & quared & 0,982382 \\
\hline $\mathrm{F}(13,47)$ & \multicolumn{2}{|r|}{198,3015} & & $2,04 \mathrm{e}-27$ \\
\hline Log-likelihood & \multicolumn{2}{|r|}{149,3168} & & $-270,6336$ \\
\hline Schwarz criterion & \multicolumn{2}{|r|}{$-244,7315$} & & $-260,8865$ \\
\hline rho & \multicolumn{2}{|r|}{$-0,276102$} & & 2,549630 \\
\hline
\end{tabular}

Source: own calculation.

Thanks to the application of multiple regression with the procedure of sequential elimination of variables using two-sided p-value (Groebner, Shannon, Fry, Smith 2003; Lucchetti 2013), we were able to reduce the set of explanatory variables to the most relevant variables. The results are presented in Table 4. 
Table 4

Model 2: OLS, using observations 2001:2-2012:4 Dependent variable: $\Delta$ GDP

\begin{tabular}{|c|c|c|c|c|c|}
\hline & Coefficient & Std. Error & t-ratio & $p$-value & \\
\hline const & 0,036616 & 0,00684003 & 5,3532 & $<0,00001$ & \\
\hline$\Delta \mathrm{E} \_2$ & 0,128273 & 0,0613516 & 2,0908 & 0,04264 & \\
\hline$\Delta \mathrm{K}$ & 0,194937 & 0,00906772 & 21,4979 & $<0,00001$ & \\
\hline dq2 & $-0,0769767$ & 0,0195981 & $-3,9278$ & 0,00031 & \\
\hline $\mathrm{dq} 3$ & $-0,0373047$ & 0,00846143 & $-4,4088$ & 0,00007 & \\
\hline Sum squared resid & 0,007301 & & S.E. of regression & & 0,013185 \\
\hline R-squared & 0,980726 & & $\begin{array}{l}\text { Adjusted R- } \\
\text { squared }\end{array}$ & & 0,978891 \\
\hline $\mathrm{F}(7,53)$ & 534,2874 & & P-value(F) & & $2,08 \mathrm{e}-35$ \\
\hline Log-likelihood & 139,4015 & & Akaike criterion & & $-268,8029$ \\
\hline Schwarz criterion & $-259,5522$ & & Hannan-Quinn & & $-265,3218$ \\
\hline rho & $-0,253832$ & & Durbin-Watson & & 2,448015 \\
\hline
\end{tabular}

Source: own calculation.

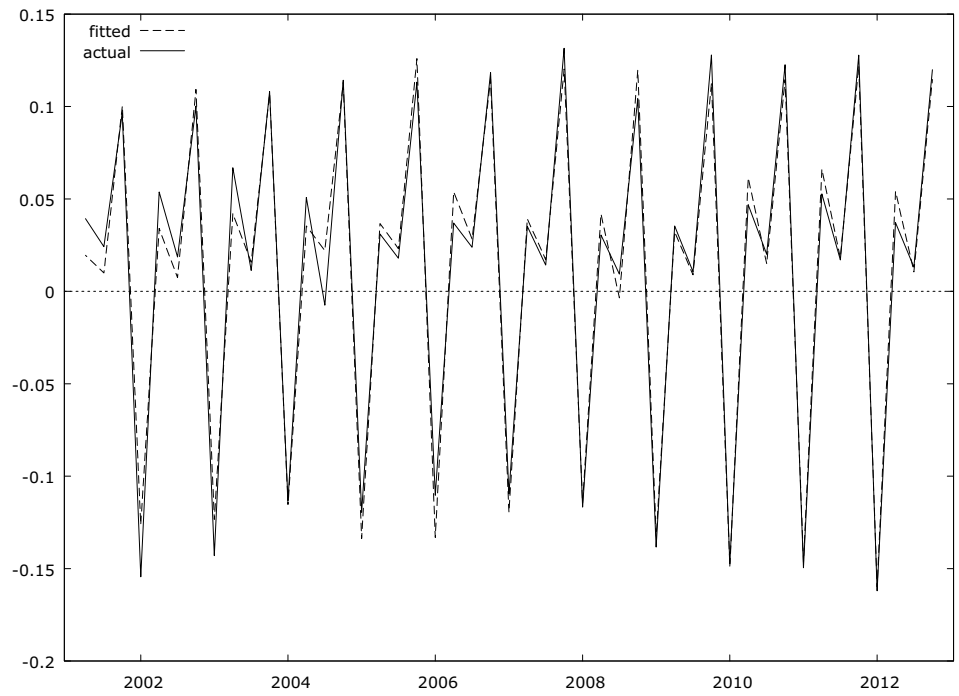

Diagram 1. Actual and fitted by Model 2 values of $\Delta$ GDP

Source: own calculation.

The value of the adjusted determination coefficient is (0.981); thus, we may point out that $98,1 \%$ of changes of the estimated variable are explained by the estimated Model 2. F-Snedecor statistics is higher than the critical value, which confirms the relevance of the presented linear regression.

The next step was to test for the correct specification of Model 2 using Ramsey's RESET test (Ramsey 1969; Thursby, Schmidt 1977). The test statistic is: $F=0.507926$, with p-value $=\mathrm{P}(\mathrm{F}(2,40)>0.507926)=$ 0.605571 , so there is no reason to reject the null hypothesis and I can confirm the correct model specification. 
After that, the model specification the heteroscedasticity of residuals was tested using the White method (White 1980; Kim, Morse, Zingales 2006). The method is a statistical test that establishes whether the residual variance of a variable in a regression model is constant: that is, for homoscedasticity. The presence of heteroscedasticity can invalidate statistical tests of significance that assume that the modeling errors are uncorrelated and normally distributed and that their variances do not vary with the effects being modeled. The result of the White test for heteroscedasticity is:

Null hypothesis: heteroscedasticity not present,

Test statistic: $\mathrm{LM}=16.1636$,

with p-value $=\mathrm{P}($ Chi-square $(11)>16.1636)=0.135163$,

the p-value is high, so it indicates that there is no reason to reject the null hypothesis and allows us to accept the homoscedasticity of regression residuals.

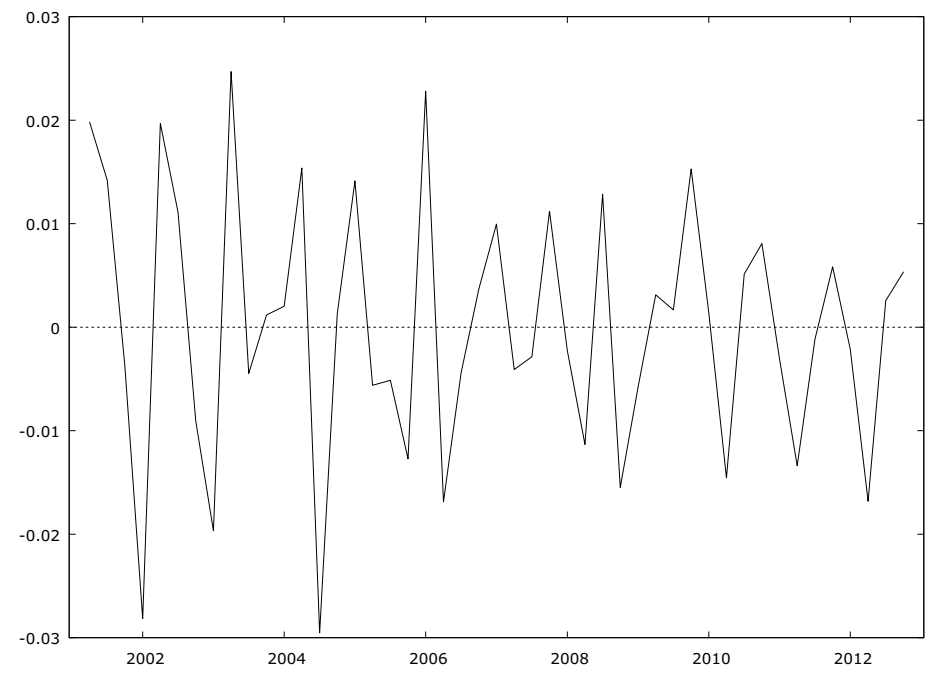

Diagram 2. Regression residuals (= observed - fitted $\Delta$ GDP)

Source: own calculation.

The calculation of confidence intervals and various significance tests for coefficients are all based on the assumptions of normally distributed residuals Sometimes, the residual distribution is distorted by the presence of a few large outliers. Since the parameter estimation is based on the minimization of squared error, a few extreme observations can exert a disproportionate influence on parameter estimates. If the error distribution is significantly non-normal, confidence intervals may be too wide or too narrow. For this reason, we conducted a test for the normality of residuals. The results are:

Null hypothesis: error is normally distributed

Test statistic: Chi-square $(2)=0.366139$

with p-value $=0.83271$

the p-value is high, so it indicates that there is no reason to reject the null hypothesis and allows us to accept the normality of residuals. 


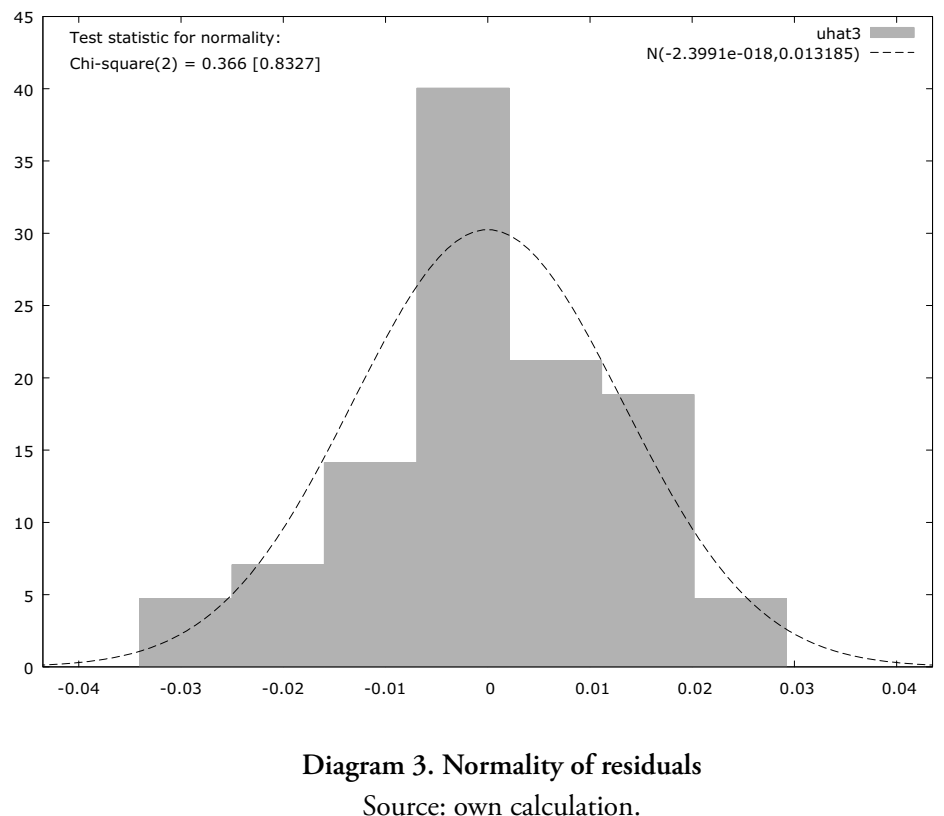

One of the fundamental assumptions in the linear regression is that the residuals are uncorrelated. In case of the regression models using time series data, the assumption of uncorrelated or independent residuals is often not appropriate. Usually, the residuals in time series data exhibit serial correlation. Such residual terms are said to be autocorrelated. The most common test against the autocorrelation of residuals in regression models is the bounds test of Durbin and Watson (Gujarati 2003; Sargan, Bhargava 1983; Dufour, Dagenais 1985). The estimated DW test statistic for the Model 2 is given in Table 4, and is 2.448. The $5 \%$ critical values for Durbin-Watson statistic for 47 observations and 4 variables equation are: $\mathrm{dL}=1.3535$ (4-dL=2.6465); $\mathrm{dU}=1.7203$ (4-dU=2.2797). The DW statistic of the model is between the critical values, so I cannot say whether there is autocorrelation or not. That is why we conducted a second test against the autocorrelation - the Quenouille test (Bartlett, Rajalakshman 1953; Rosenhead 1968). The estimated Quenouille test statistic is given in Table 4 and is -0.253832 (rho). The $5 \%$ critical value for Quenouille statistic for 47 observations is 0.2861 ( rho $_{\text {critical }}$ ). The estimated rho statistic absolute value of the model is lower than the critical value, so we can confirm that the residuals are uncorrelated.

The last step in the regression testing was the parameter stability test CUSUM. Parameter stability is equivalent to model stability, because an econometric model is described by its parameters. Model instability may be caused, for example, by the omission of an important variable. The instability of a model causes difficulties in the interpretation of regression results (Hansen, 1992). The results of the CUSUM test for parameter stability are:

Null hypothesis: no change in parameters

Test statistic: Harvey-Collier $\mathrm{t}(41)=-0.591813$

with $\mathrm{p}$-value $=\mathrm{P}(\mathrm{t}(41)>-0.591813)=0.557225$

the p-value is high, so it indicates that there is no reason to reject the null hypothesis and allows us to confirm the parameter stability of Model 2. Diagram 4 reports the results of the parameter stability test within a $95 \%$ confidence band. 
The OLS estimation assumptions imply that the variance-covariance matrix of the random component is diagonal, which means that the random components of the respective periods are not correlated with each other, and the variance of the random component is fixed and finite. In addition, a random component in each period is normally distributed with the expected value 0 and finite.

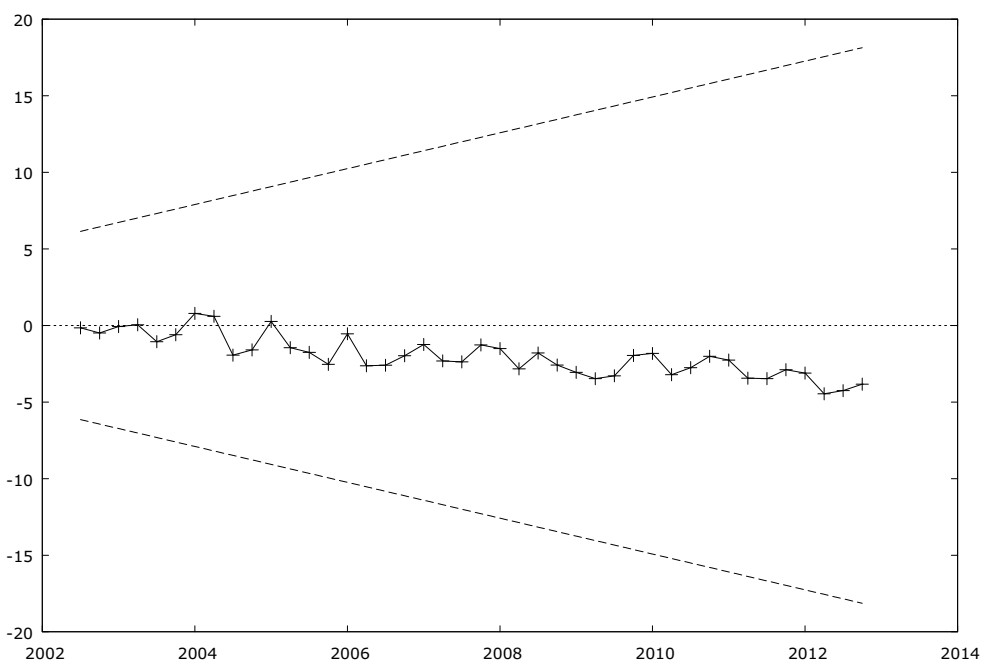

Diagram 4. CUSUM plot with $95 \%$ confidence band

Source: own calculation.

The modeling we carried out meets all the requirements of the proper OLS estimation. There is no autocorrelation of residuals, the variance of residuals is constant. The residuals of the model have normal distribution with the expected value 0 . In addition, we used stationary variables for the estimation of the equation, which was analyzed with two statistical tests.

Since the estimated model of the Polish economic growth with the application of electricity consumption as one of the explanatory variables meets all the conditions of proper estimation, it undoubtedly has reliable economic interpretation.

\section{CONCLUSIONS}

In the study, we attempted to analyze the causal relationship between electricity consumption and economic growth in Poland. The analysis was based on Granger-causality test, which indicated that that the Granger-causality is running in both directions between Electricity Consumption and Gross Domestic Product, so it runs both from energy consumption to economic growth and from economic growth to energy consumption. These conclusions stand in contradiction to the neo-classical argument that energy is neutral to output growth.

Based on the obtained results, we developed a one-sector aggregate production function using OLS regression using electricity consumption as one of the input variables. The estimation has proven that energy 
consumption determined the economic growth in Poland over the sample period of 2000 to 2012. The evaluated regression model includes the following variables:

- growth rates of Eelectricity Consumption with 2 quarters leading,

- growth rates of Gross Fixed Capital in real prices - coincident.

The above-mentioned variables make up a regression function Model 2, which explains about 98\% of the variability of the economic growth in Poland. All econometrical tests of Model 2 have proved the correctness of the model specification, which enables the reliable interpretation of the model in economic terms. The Electricity Consumption is a pro-growth variable, which means that the increase of the electricity consumption growth rate causes the increase of economic growth. The second variable - Gross Fixed Capital is a pro-growth variable as well. The increase of the capital growth rate causes the increase of economic growth in Poland.

To sum up, the empirical results of the study show that the economic growth of Poland is energy-dependent, so one can state that electricity consumption is a limiting factor to economic growth of Poland. It means that the energy policy may have a strong negative impact on the economic growth and development of the Polish economy.

\section{REFERENCES}

Altinay, G., Karagol, E. (2005), Electricity consumption and economic growth: Evidence from Turkey, Energy Economics, 27, pp. 849-856.

Bartlett, M. S., Rajalakshman, D. V. (1953), Goodness of Fit Tests for Simultaneous Autoregressive Series, Journal of the Royal Statistical Society. Series B (Methodological), Vol. 15, No. 1, pp. 107-124.

Cheng, B.S. (1995), An Investigation of Cointegration and Causality between Energy Consumption and Economic Growth, Journal of Energy and Development, 21, pp. 73-84.

Dufour J., Dagenais, M.G. (1985), Durbin-Watson tests for serial correlation in regressions with missing observations, Journal of Econometrics, 27, pp. 371-381.

Fatai, K., Oxley, L., Scrimgeour, F.G. (2004), Modelling the causal relationship between energy consumption and GDP in New Zealand, Australia, India, Indonesia, The Philippines and Thailand, Mathematics and Computers in Simulation, 64, pp. 431-445.

Ferguson, R., Wilkinson, W., Hill, R. (2000), Electricity use and economic development, Energy Policy, 28, pp. 923-934.

Granger, C. W. J. (1980), Testing for Causality: A Personal Viewpoint, Journal of Economic Dynamics and Control, Vol. 2, pp. 329-352.

Granger, C. W. J. (1969), Investigating Casual Relations by Econometric Models and Cross-Spectral Methods, Econometrica, Vol. 37, No. 3, pp. 424-438.

Groebner, D. F., Shannon, P. W., Fry, P. C., Smith, K. D. (2003), Business Statistics: A Decision-Making Approach, December 31, ISBN-10: 013179633X, ISBN-13: 978-0131796331.

Gujarati, D.N. (2003), Basic econometrics, 4th ed., McGraw-Hill, Boston, USA.

Hansen, B.E. (1992), Testing for Parameter Instability in Linear Models, Journal of Policy modeling, 14(4), pp. 517-533.

Hatemi, A., Irandoust, M., (2005), Energy Consumption and Economic Growth in Sweden: A Leveraged Bootstrap Approach, 1965-2000, International Journal of Applied Econometrics and Quantitative Studies, 4, pp. 1-20.

Kasperowicz, R. (2012), The Co-occurrence of Cyclical Fluctuations of Economic Aggregates in Polisch Manufacturing Industry, Actual Problems of Economics, Kijów, Vol. 2, No. 7, pp. 63-72.

Kasperowicz, R. (2013), Forecasting the consumption of electricity by Polish industry, Actual Problems of Economics, Kijów, Vol. 2, No. 1, pp. 81-90. 
Kim, E.H., Morse, A., Zingales, L. (2006), What Has Mattered to Economics since 1970, Journal of Economic Perspectives, 20 (4), pp. 189-202.

Kwiatkowski, D., Phillips, P. C. B., Schmidt, P., Shin, Y. (1992), Testing the Null Hypothesis of Stationarity against the Alternative of a Unit Root, Journal of Econometrics 54, pp. 159-178.

Lee, C., Chang, C. (2005), Structural breaks, energy consumption, and economic growth revisited: Evidence from Taiwan, Energy Economics, 27, pp. 857-872.

Lucchetti, R. (2013), Gretl Command Reference, Gnu Regression, Econometrics and Time-series Library, Allin Cottrell Department of Economics Wake Forest University, January.

Oh, W., Lee, K. (2004), Causal relationship between energy consumption and GDP revisited: the case of Korea 19791999, Energy Economics, 26, pp. 51-59.

Ramsey, J.B. (1969), Tests for Specification Errors in Classical Linear Least Squares Regression Analysis, Journal of the Royal Statistical Society, Series B, 31 (2), pp. 350-371.

Rosenhead, J. (1968), An Extension of Quenouille's Test for the Compatibility of Correlation Structures in Time Series, Journal of the Royal Statistical Society. Series B (Methodological), Vol. 30, No. 1, pp. 180-184.

Sargan, J.D., Alok Bhargava, (1983), Testing residuals from least squares regression for being generated by the Gaussian random walk, Econometrica, 51, pp. 153-174.

Soytas, U., Sari, R. (2003), Energy consumption and GDP: causality relationship in G-7 countries and emerging markets, Energy Economics, 25, pp. 33-37.

Thursby, J.G., Schmidt, P. (1977), Some Properties of Tests for Specification Error in a Linear Regression Model, Journal of the American Statistical Association, 72, pp. 635-641.

White, H. (1980), A Heteroskedasticity-Consistent Covariance Matrix Estimator and a Direct Test for Heteroskedasticity, Econometrica, 48 (4), pp. 817-838.

Wolde-Rufael, Y. (2006), Electricity consumption and economic growth: a time series experience for 17 African countries, Energy Policy, 34, pp. 1106-1114.

Yoo, S.H. (2005), Electricity consumption and economic growth: evidence from Korea, Energy Policy, 33, pp. 16271632. 